\title{
CONCEPÇÕES TEÓRICAS E PESQUISAS EDUCACIONAIS: OS DESAFIOS PARA SUPE- RAR O SENSO COMUM
}

\author{
Dayane de Freitas Colombo Rosa ${ }^{1}$, Roseli Gall do Amaral da Silva ${ }^{2}$.
}

${ }^{1}$ Universidade Estadual de Maringá - UEM, Programa de Pós Graduação em Educação, Maringá, PR. E-mail: dayemarcio@hotmail.com. ${ }^{2}$ Universidade Tecnológica Federal do Paraná - UTFPR, Apucarana, PR. E-mail: amararose$\underline{\text { li@gmail.com }}$

\section{RESUMO}

O objeto de pesquisa desse trabalho são as concepções teóricas da pesquisa em educação, mais especificamente as correntes positivista e materialista da história, o objetivo é refletir sobre os desafios enfrentados por alunos de programas de pesquisa em educação e/ou do curso de pedagogia em superar o senso comum nas suas produções a fim de discutir sobre os objetivos mercadológicos que legitimam o não ensino e/ou o ecletismo dessas concepções teórico-metodológicas. Parte-se do pressuposto de que a produção do conhecimento é um processo histórico que é tecido na trama da existência humana para atender as necessidades da organização da vida e, não é um fenômeno constituído de forma natural e linear sem ligação com o movimento concreto da história. Dessa forma, buscou-se responder a questão: quais os desafios enfrentados hoje na produção acadêmica da área educacional em relação ao método? Para tanto, o procedimento metodológico adotado é a pesquisa bibliográfica, as referências de leitura são em especial Comte (1978), Marx e Engels (1986), Saviani (2003/2002), Nagel (2004) e Pereira (2003). A partir da concepção teórico metodológica adotada, as pesquisas se constituem diferentemente, pois a concepção do que é ciência, homem, educação e desenvolvimento humano atendem aos objetivos da prática social do momento histórico ao qual pertencem, portanto, saber diferenciá-las e compreendê-las para além da causalidade aparente contribui para o processo de luta contra a alienação e superação do senso comum.

Palavras-chave: Pesquisa, Educação, Método.

\section{THEORETICAL CONCEPTIONS AND EDUCATIONAL RESEARCH: THE CHALLENGES TO OVERCOME THE COMMON SENSE}

\begin{abstract}
The purpose of this research is the theoretical conceptions of research in education, more specifically the positivist and materialist currents of history, the objective is to reflect on the challenges faced by students of educational research programs and / or pedagogy course in overcoming common sense in their productions in order to discuss the marketing objectives that legitimize the non-teaching and / or eclecticism of these theoretical-methodological conceptions. It is assumed that the production of knowledge is a historical process that is woven into the fabric of human existence to meet the needs of the organization of life, and is not a phenomenon constituted in a natural and linear way without connection with the concrete movement of history. Thus, we sought to answer the question: what challenges do we face today in the academic production of the educational area in relation to the method? For this, the methodological method adopted is the bibliographical research, the references of reading are especially Comte (1978), Marx and Engels (1986), Saviani (2003/2002), Nagel (2004) and Pereira (2003). From the theoretical methodological conception adopted, the researches are constituted
\end{abstract}


differently, since the conception of what is science, man, education and human development meet the objectives of the social practice of the historical moment to which they belong, and to understand them in addition to the apparent causality that contributes to the process of struggle against alienation and overcoming of common sense.

Keywords: Research, Education, Method.

\section{INTRODUÇÃO}

As dificuldades enfrentadas na elaboração das produções acadêmicas na área educacional e as queixas sobre a qualidade dessas produções tem sido tema de discussão entre diversos intelectuais da contemporaneidade (NAGEL,2004). Essas discussões explicitam que uma das maiores dificuldades enfrentadas é a superação do senso comum e, que aumentam a cada dia a produção de pesquisas na área educacional que não apresentam uma concepção teórica metodológica no decorrer da elaboração do relatório de pesquisa ou, o que apresentam é uma mistura dessas concepções, o que dificulta identificar a identidade do trabalho e seu caráter científico.

Tendo como ponto de partida a problemática vivida e as leituras realizadas das obras de Comte em "Discurso sobre o espírito positivo" de 1978 e "A Ideologia Alemã" de Marx e Engels de 1986, investigou-se as formas diferenciadas de interpretação da realidade e os métodos de pesquisa utilizados para a análise das teorias educacionais, o que justifica a escolha do objeto de pesquisa desse trabalho, as concepções teóricas da pesquisa em educação, mais especificamente as correntes positivista e materialista da história.

Diante dessa constatação, buscou-se responder a indagação: quais os desafios enfrentados hoje para a produção acadêmica na área educacional? E estão relacionados aos princípios que primam pelo espontaneísmo? O objetivo central foi refletir sobre as dificuldades enfrentadas em superar o senso comum nas produções acadêmicas da área educacional.

\section{METODOLOGIA}

O procedimento técnico metodológico adotado foi bibliográfico. As leituras realizadas proporcionam analisar o objeto em discussão por suas múltiplas conexões e compreendê-lo além da causalidade aparente, assim como contribuíram para conhecer as diferentes contribuições científicas disponíveis sobre o tema abordado.

\section{RESULTADOS}

No contexto do século XIX, em que há uma vertiginosa diminuição de postos de trabalhos e juntamente com um discurso de que o nível de desemprego está elevado não devido a transformações profundas dos meios de produção, mas pela especificação das novas tecnologias empregadas na produção que passam a exigir trabalhadores mais qualificados, e uma equipe de trabalho competitiva e com espírito de encarar as mudanças, na qual a culpabilidade de altas taxas de desemprego é do próprio trabalhador que não se preparou eficientemente para se recolocar no mercado de trabalho, se observa o aumento de produções acadêmicas que primam pela descrição de um fenômeno particular, e que muitas vezes não superam o senso comum. Mazzotti (2001), no que se refere as dificuldades das pesquisas em educação destaca:

[...] (a) pobreza teórico - metodológica na abordagem dos temas, com um grande número de estudos puramente descritivos e/ou "exploratórios"; (b) pulverização e irrelevância dos temas escolhidos; (c) adoção acrítica de modismos na seleção de quadros teóricos - metodológicos; (d) preocupação com a aplicabilidade imediata dos resultados; e (e) divulgação restrita dos resultados e pouco impacto sobre as práticas (MAZZOTTI, 2001, p.2).

Nesta perspectiva, Lízia Helena Nagel (2004) em “Educação Pós-Moderna: interesses e Aporias", argumenta que se a historiografia examinar essas problemáticas "pode revelar não só os 
problemas que estão sendo discutidos como relevantes para a área como pode informar sobre os caminhos e as contradições que delimitam seus propósitos" (NAGEL, 2004, p.1).

Para a autora, no final do século XX foi realizada uma intensa campanha para que a História da Educação superasse a velha historiografia e foi proposto a liberdade crítica de cada sujeito em sua individualidade, enfatizando o subjetivismo ao se fazer ciência, ou seja, "colocam em relevo a ética, a estética e a esperança ao invés do conhecimento" (NAGEL, 2004, p.11, grifo da autora"). E em 2006 ao observar as dissertações e teses publicadas, assim como artigos publicados em revistas renomadas, observa-se a concretização de novas propostas, segundo a autora "apregoadas como necessárias ao desenvolvimento do saber relativo à área da educação" (NAGEL, 2004, p.1).

Isto posto, faz-se necessário problematizar como essa realidade vivida está relacionada com os princípios do espontâneismo e da relatividade que foram construídos historicamente pela classe dominante para manutenção da sua dominação. Pois vive-se em um tempo em que segundo ALVES (2009), a forma de acumulação do capital, busca apropriar-se também da subjetividade do indivíduo, fazendo com que essa subjetividade seja os ideais do discurso ideológico desse sistema de produção, sendo totalmente uma forma de manipulação, no qual a educação fomenta as aprendizagens individuais e a criatividade para satisfazer as necessidades imediatas e não o processo histórico construído socialmente pelo conjunto dos homens. Assim, corrobora-se com a tese levantada por Nagel (2004, p.2), de que "a relação educativa enquanto expressão das relações sociais não interessam à sociedade capitalista". Sobre essa questão, a autora enfatiza que:

$\mathrm{O}$ interesse, como sempre, passa a ser definido pelo singular, pelo particular, agora, no âmago do neoliberalismo, sob a sombra, atual, do "limite do pensável". Da mesma forma, o mito do indivíduo autocriador se acirra na pedagogia, carregando, com tal lógica, as contradições na teoria e na prática educativa da atualidade (NAGEL, 2004, p.2).

Dessa forma, os alunos da área das ciências humanas, mais específica a área da educação, estão recebendo uma formação que ressalta o conhecimento técnico desvinculado do teórico, que enaltece as disciplinas de metodologia práticas e despreza as disciplinas teóricas essenciais que permite entender as contradições inerentes ao processo de construção da vida de acordo com Marx e Engels, sendo elas a história e a filosofia, em outras palavras, os alunos estão recebendo uma formação que não proporciona "dominar o que os dominantes dominam" (MARX; ENGELS, 1986, p.56), ou seja, o conhecimento, a ciência. E nesse sentido, a filosofia da práxis é um movimento prioritariamente prático que se fundamenta teoricamente, fortalece-se na teoria para esclarecer o sentido, dar direção à prática. E, a prática tem primado pela teoria por ser ela que a origina. (SAVIANI, 2003, p. 142). Segundo Gramsci, a principal tarefa da Filosofia da Práxis, ou do materialismo histórico, é desvendar o conhecimento a todas as classes, levando-as do senso comum ao pensamento filosófico. Gramsci discute a questão teoria-prática, (ou a divisão entre trabalho manual e intelectual) levantando a dualidade educacional, onde elite e classes operárias são tratadas de formas diferentes.

A esse respeito, Saviani (2003), levanta a questão do saber sistematizado ser propriedade privada a serviço do grupo dominante, e estabelece a diferença entre a produção do saber e a sistematização do saber. A produção do saber é social, logo, ocorre no interior das relações sociais. A elaboração do saber implica expressar de forma sistematizada o saber que surge da prática social. Essa expressão elaborada supõe o domínio dos instrumentos de elaboração e sistematização.

Destarte, um dos desafios para superar o senso comum é uma formação que possibilite o aluno compreender as concepções teórico metodológicas e a que fins elas buscam atender (SAVIANI, 2002), faz-se necessário entender como os caminhos disponíveis a serem trilhados para responder os problemas de pesquisa delimitados concebem a sociedade, o homem e a educação.

Até porque tende-se hoje, nas pesquisas em educação, a um ecletismo teórico; tende-se também a considerar e até a legitimar estudos que não conseguem superar o mero "senso 
comum", o mero "saber comum", e os quais, se por um lado perpetuam confusões, por outro alimentam tiragens editoriais que têm, sobretudo objetivos mercadológicos (PEREIRA, 2003, p.142).

Podemos relacionar essas confusões que perpetuam explicitados pela a autora citada acima com a formação de algumas instituições que "[...] preocupadas em satisfazer interesses práticos imediatos, predominam sobre a escola formativa, imediatamente desinteressada [...]" (GRAMSCl, 2000, p. 49) e que são apregoadas pelo governo como um "[...] tipo de escola que aparece e é louvado como democrático, quando na realidade, não só é destinado a perpetuar as diferenças sociais, como ainda a cristaliza-las[...] (GRAMSCI, 2000, p. 49).

O fato é que as produções científicas da área educacional estão assumindo formas e traços característicos do momento vivido pelos sujeitos, que na realidade, são os produtores da consciência. Ademais, as produções acadêmicas estão sujeitas as contingências humanas em que sua aparição se torna possível, em outras palavras, as ideias dos homens não estão de modo algum fora do movimento da luta de classes.

\section{DISCUSSÃO}

A palavra "ciência" vem do latim scientia, que significa conhecer. O conhecimento científico adquire diferentes formas no movimento da história, e o entendimento desse conhecimento como um "[...] saber metódico e rigoroso, isto é, um conjunto de conhecimentos metodicamente adquiridos, que tem por finalidade propor uma explicação racional e objetiva da realidade, mediante procedimentos de controle experimental (JAPIASSÚ, MARCONDES, 1996, p.36) é uma concepção que ganha força em um contexto de complexo processo de transformações materiais, que de forma mediatizada foram ganhando contornos característicos de uma nova base material leiase capitalismo.

É no cenário de transição de feudalismo para capitalismo, de luta entre o velho e o novo, de necessidade em desenvolver conhecimentos que possibilitem a construção de novos instrumentos que atendam as novas necessidades do novo modo de organização da vida, que emerge a discussão sobre a necessidade de métodos precisos de investigação e explicação na ciência naturais conduzindo assim, à tentativa de uso de métodos matemáticos experimentais.

As discussões relacionadas ao método se estabelecem com maior intensidade nesse contexto, pois aos poucos as preocupações voltam-se para as questões do conhecer e não do ser. $\mathrm{Na}$ sua raiz epistemológica a palavra método provém do latim methodus, que quer dizer estudo metódico de uma ciência, caminho, procura, investigação. Segundo o dicionário básico de filosofia de Hilton Japiassú e Danilo Marcondes (1996), método significa "(lat. tardio methodus, do gr. methodos, de meta: por, através de; e hodos: caminho) 1. Conjunto de procedimentos racionais, baseados em regras que visam atingir um objetivo determinado" (JAPIASSÚ; MARCONDES, 1996, p. 130).

Nesse sentido, método é um caminho percorrido para alcançar determinado objetivo e uma forma de conceber o mundo, ou seja, uma concepção teórica que conceitua o homem, a sociedade e a educação. No processo histórico de consolidação da sociedade moderna houveram importantes contribuições de pensadores e cientistas que problematizaram a questão do método, dentre os quais destacamos Descartes (1596-1650) e Bacon (1558-1626).

Parte-se do pressuposto de que educação e método são questões intimamente relacionadas, pois, o trabalho educativo percorre um caminho, fundamenta-se em uma concepção teórico metodológica. Nesse sentido, faz-se necessário expor que corroboramos com a ideia de que a educação é determinada historicamente pelo modo de produção dominante e de que o seu objeto consiste por um lado em identificar quais os elementos culturais precisam ser assimilados pelos indivíduos e de outro descobrir qual a forma mais adequada para atingir esse objetivo, ou seja, o método. 
O recurso à Epistemologia para dizer o que é Educação [...] se mostra um esforço para definir o objeto da Educação a partir de uma construção teórica que, não sendo neutra, vai influir no resultado desta busca, a ponto de tornar diferentes os objetos segundo a perspectiva teórica pela qual são vistos (NACHONICZ, 2002, p. 56).

Nesta perspectiva, partimos do pressuposto de que as pesquisas acadêmicas educacionais se constituem diferentemente, dependendo do método abordado. Dessa forma, as produções acadêmicas que tomam por base o método positivista defendem a neutralidade, objetividade científica e a ideia de que os fatos falam por si, são pesquisas quantitativas e descritivas que retiram dos estudos os sujeitos das suas relações sociais. Segundo Pereira (2003) em "Concepções Teóricas da Pesquisa em Educação: Superando as dificuldades", as pesquisas positivistas:

Constituem - se, portanto, em dados isolados da sua gênese, do seu processo, da sua própria história. Apresentam - se como "radiografias", "retratos" sem cenário, sem perspectiva outra que não seja a da linearidade, de forma a estabelecer relações regulares que tendem a um sentido hipoteticamente colocado (PEREIRA, 2003, p. 135).

Este princípio pode ser observado quando Auguste Comte argumenta que:

Cada um sabe que, em nossas explicações positivas, até mesmo as mais perfeitas, não temos de modo algum a pretensão de expor as causas geradoras dos fenômenos, posto que nada mais faríamos então além de recuar a dificuldade. Pretendemos somente analisar com exatidão as circunstâncias de sua produção e vinculá-las umas às outras, mediante relações normais de sucessão e de similitude (COMTE, 1978, p. 43).

O mundo para Comte deve ser ciência, a ciência que está a serviço da burguesia, por isso, seu método objetiva a construção de um indivíduo que sabe e aceita a sua condição na sociedade como explicação das ciências naturais onde os menores devem estar a serviço dos maiores.

As produções científicas realizadas que partem dos princípios do materialismo histórico dialético proposto por Marx e Engels em “A Ideologia Alemã" de 1986, como caminho a ser seguido para a solução de seus problemas de pesquisa, preponderam que se deve "estudar e elaborar incessantemente a "história dos homens" em conexão com a história da indústria e das trocas" (MARX; ENGELS, 1986, p. 24).

Para a professora Maria de Fátima Rodrigues Pereira (2003):

As pesquisas que se orientam à luz desta perspectiva visam entender os fenômenos da educação na gênese e movimento dos próprios processos históricos, ou seja, não são "retratos" sem cenários como na perspectiva positivista: também não são somente entendidos subjetivamente nos contextos, mas se desvelam na própria gênese e nos próprios processos históricos evidenciando constituições, permanências, mudanças que nos permitem, a título de exemplo, entender quando no estudo da educação nos damos conta de que velhas questões do tecnicismo estão recolocadas em tempos de neoliberalismo. Afinal, o capital reestrutura - se e busca sedimentar - se, dentre outros meios, pela educação (PEREIRA, 2003, p. 141).

Dessa forma, compreende que o método seguido, ao fazer uma pesquisa acadêmica proporciona entendimento de forma diferenciada de interpretação da realidade e, portanto, devem ser analisados suas concepções de mundo, sociedade, homem e educação e entendê-los para além da causalidade aparente. Nagel (2004), explicita que após os anos 2006, os autores que passam a ser referenciados são autores que primam pela subjetividade, pragmatismo, espontaneísmo e "a negação, de forma descontextualizada, de forma a-histórica, da filosofia quer de Platão, de Descartes, de Locke (de Kant, em alguns casos), e de Marx, sempre denunciado como 'dogmático' e ortodoxo" (NAGEL, 2004, p.10).

\section{CONCLUSÃO}


Em tempos neoliberais a maioria das produções da academia assumem contornos bem definidos, pois, quando não articulam o objeto de pesquisa com o movimento concreto da história e primam pela descrição de fatos particulares, estão contribuindo para atender as necessidades do modo de produção vigente, que consiste em manipular a subjetividade dos indivíduos, fazendo com que estes vejam a sociedade e o mundo de forma individual colocando o desejo, o querer e a disputa acima do ser social, criando uma identidade pessoal e não social.

Portanto, investigar as concepções teóricas da pesquisa em educação, pode contribuir para fomentar discussões sobre a qualidade das produções acadêmicas da contemporaneidade que envolvem a educação, e a necessidade de uma formação docente para uma práxis mais efetiva e transformadora, que possibilite a formação de uma consciência que supere o senso comum.

As considerações finais deste trabalho não se encerram em si mesmas, mas abrem caminho para novas e sucessivas discussões, incentivando, portanto, sua continuidade.

\section{REFERÊNCIAS}

ALVES, Giovani. Trabalho e Subjetividade. São Paulo: Boitempo, 2009.

COMTE, Auguste. Discurso sobre o espírito positivo. In: COMTE, Auguste. Curso de filosofia positiva; Discurso preliminar sobre o conjunto do positivismo; Catecismo positivista. São Paulo: Nova Cultural, 1978. p.41-94. (Os pensadores).

GRAMSCl, Antonio. Apontamentos e notas dispersas para um grupo de ensaios sobre a história dos intelectuais. In Cadernos do Cárcere. Volume 2. Rio de Janeiro:Civilização Brasileira. 2000.p.13-53.

JAPIASSÚ, Hilton; MARCONDES, Danilo. Dicionário básico de filosofia. 3ạ ed. Rio de Janeiro: Jorge Zahar Ed., 1996.

MARX, Karl; ENGELS, Friedrich. A ideologia alemã (Feuerbach). 5. ed. Tradução de José Carlos Bruni e Marco Aurélio Nogueira. São Paulo: Hucitec, 1986. p.15-77.

MAZZOTTI, Alda Judith Alves. Relevância e aplicabilidade da pesquisa em educação. Cadernos de pesquisa, no 113, julho/2001.

NACHONICZ, Lilian Anna. A epistemologia da educação. Revista Educar, Curitiba, n. 19, 2002.

NAGEL, Lizia Helena. Educação pós-moderna: interesses e aporias. In Campinas: Unicamp, s/dp, p. $1-13$.

PEREIRA, M. F. R.. Concepções Teóricas da Pesquisa em Educação: Superando Dificuldades. In: Joisé Claudinei Lombardi. (Org.). Globalização, Pós- modernidade e Educação, história, filosofia e temas transversais. 3ed.Campinas: Autores Associados, 2003, v. 1, p. 129-143.

SAVIANI, Dermeval. Educação: do senso comum à Consciência filosófica. 14 a ed. Campinas: Autores Associados. 2002.

Escola e Democracia. 29a ed. Campinas: Autores associados. 1995.

Pedagogia Histórico-crítica: primeiras aproximações. 8a ed.Campinas. SP: Autores Associados, 2003. 
